\title{
Flower Density Is More Important Than Habitat Type for Increasing Flower Visiting Insect Diversity
}

\author{
L. A. Scriven, M. J. Sweet, and G. R. Port \\ School of Biology, Ridley Building, Newcastle University, Newcastle upon Tyne NE1 7RU, UK \\ Correspondence should be addressed to L. A. Scriven; l.a.scriven@ncl.ac.uk
}

Received 28 February 2013; Revised 6 May 2013; Accepted 8 May 2013

Academic Editor: J. J. Wiens

Copyright ( 2013 L. A. Scriven et al. This is an open access article distributed under the Creative Commons Attribution License, which permits unrestricted use, distribution, and reproduction in any medium, provided the original work is properly cited.

\begin{abstract}
Declines in flora and fauna are well documented and highlight the need to manage available habitats to benefit local biodiversity. Between May and September in 2011 the number, composition, and diversity of flower visiting insects were assessed across eight sites, representing a range of habitats within an industrial site in the North East of England, UK. There was no significant difference in insect assemblages between the sites selected, but there was a significant difference between the months surveyed. Flower density was highlighted as the most important factor driving these changes between months and indicates that flower density is more important to a site for insect diversity than the presence of specific habitats. Analysis of the insect communities each month allowed comparison of dominant insects to the flower density data, highlighting sites where management intervention could be initiated to benefit insect diversity, or alternatively specific management plans to encourage target species. Furthermore, this study highlights the importance of correct data interpretation to answer specific management objectives and recommends analysing the insect community interactions to determine the dominant species present prior to undertaking any management of the site in question.
\end{abstract}

\section{Introduction}

As a result of human influences, habitats and ecosystems are continually fragmented by factors such as city expansion, and agricultural intensification $[1,2]$. Areas such as gardens, parks, brownfield sites, and working industrial sites are becoming important "islands" for wildlife between the everincreasing urbanised areas. However, these sites require management to conserve biodiversity and to provide an optimum habitat network for species [3]. Sites left unmanaged over long periods of time can become dominated by rank grasses and pernicious weeds, reducing the biodiversity and value of the habitat [4].

Previous studies have highlighted the impacts of environmental management schemes and the effects of habitat fragmentation on biodiversity within agricultural environments [5-7]. Additionally, the importance of gardens and parks for pollinating species within urbanised areas is becoming more apparent [8-10]. Nevertheless, the importance of industrial areas has not yet been considered. Despite industrial sites often being heavily utilised, a large proportion have the potential to create wildlife refuges within an urban and agriculturally dominant landscape. Industrial sites are found worldwide and frequently cover a large expanse of land, usually incorporating varied unmanaged habitats.

The aluminium smelter site at Lynemouth, UK, incorporates a range of these different habitats including scrub, grassland, and wetland. Although it is widely accepted that increased habitat variety often results in higher species diversity [11-13], factors such as the botanical structure and flower density within the site can be more influential on insect assemblages than distinct habitat types [14, 15]. This highlights further questions as to what drives these trends within such habitats. For example, how variable do habitats need to improve insect diversity? Does habitat connectivity affect habitat quality? And importantly, if a specific management strategy was implemented at sites such as Lynemouth, would it be possible to increase diversity of insect species present?

The success of any programme to enhance biodiversity is dependent on how people manage land and invest in development. Within large companies, where employees have been encouraged to take an interest in biodiversity, site action plans have become successful. However, an important step before management strategies can be employed is to determine the 
TABLE 1: Description of the eight sites used within the study, highlighting the name given, location, habitat type, and a description of the dominant plant species present within each site.

\begin{tabular}{|c|c|c|c|}
\hline Site & $\begin{array}{c}\text { Location } \\
\text { (British National Grid) }\end{array}$ & $\begin{array}{l}\text { Habitat area } \\
\text { (hectares) }\end{array}$ & Description \\
\hline $\begin{array}{l}\text { Flower Rich } \\
\text { (FR) }\end{array}$ & NZ29350 BNG89685 & 0.55 & $\begin{array}{l}\text { Well drained, poor quality soil. Flowering species such as Lotus } \\
\text { corniculatus (Birds foot Trefoil), Trifolium pratense (Red clover), } \\
\text { and Dactylorhiza incarnata (Marsh orchid) present }\end{array}$ \\
\hline $\begin{array}{l}\text { Mown Grassland } \\
(\mathrm{MG})\end{array}$ & NZ29674 BNG89205 & 0.30 & $\begin{array}{l}\text { Lawn areas regularly mown and dominated by Taraxacum } \\
\text { officinale (Dandelions), Bellis perennis (daisies). Backing onto long } \\
\text { unmanaged grassland surrounded by farmland }\end{array}$ \\
\hline $\begin{array}{l}\text { New Hedge } \\
(\mathrm{NH})\end{array}$ & NZ29741 BNG89191 & 0.20 & $\begin{array}{l}\text { Running alongside wheat field. Consisting of Rosa canina } \\
\text { (dogrose), crataegus sp. (hawthorn), Prunus spinosa (blackthorn), } \\
\text { and Rubus fruticosus (blackberry) }\end{array}$ \\
\hline $\begin{array}{l}\text { Old Hedge } \\
(\mathrm{OH})\end{array}$ & NZ28918 BNG89685 & 0.20 & $\begin{array}{l}\text { Single species hedge hawthorn, bordering Brassica napus (oil seed } \\
\text { rape) field, with weed species such as Matricaria discoidea } \\
\text { (pineapple weed) and Leucanthemum vulgare (oxeye daisy) in the } \\
\text { field no flowering plants in the field margin }\end{array}$ \\
\hline $\begin{array}{l}\text { Plantation Woodland } \\
(\mathrm{Pl})\end{array}$ & NZ29135 BNG89703 & 0.62 & $\begin{array}{l}\text { Urtica dioica (Nettles) as understory plants, } 2 \mathrm{~m} \text { separated poplar } \\
\text { trees with occasional Acer pseudoplatanus (sycamore), Quercus } \\
\text { robur (oak), and Sorbus aria (whitebeam) }\end{array}$ \\
\hline $\begin{array}{l}\text { Pond } \\
\text { (Po) }\end{array}$ & NZ29384 BNG89278 & 0.55 & $\begin{array}{l}\text { Pond surrounded by Vicia sativa (vetches), Anthriscus cerefolium } \\
\text { (chervil), Oenanthe crocata (Dropwort water hemlock), Rubus sp. } \\
\text { (blackberry), and Centaurea nigra (common knapweed) }\end{array}$ \\
\hline $\begin{array}{l}\text { Ridge and Furrow } \\
\text { Grassland } \\
(\mathrm{RF})\end{array}$ & NZ29001 BNG89671 & 0.60 & $\begin{array}{l}\text { Heracleum sphondylium (Hogweed) dominated grassland with tall } \\
\text { dominant grasses such as Elymus repens (couch grass) and } \\
\text { Arrhenatherum elatius (false oat grass) surrounded by farmland }\end{array}$ \\
\hline $\begin{array}{l}\text { Woodhorn Woodland } \\
\text { (WW) }\end{array}$ & NZ29079 BNG89616 & 0.55 & $\begin{array}{l}\text { Older woodland trees including A. pseudoplatanus and Q. robur, } \\
\text { with an understory of Hyacinthoides nonscripta (bluebells), } \\
\text { Galanthus sp. (snowdrops), and Rubus sp. (blackberry) }\end{array}$ \\
\hline
\end{tabular}

value of the site for biodiversity. By assessing different habitats and understanding which species are utilising these areas, informed decisions on future land management can be made.

Therefore, this study aims to assess flower visiting insects to determine the value of the Lynemouth smelter for pollinators and other flower visiting insects. Specifically we aimed at determining: (i) which flower visiting insects are active at the Lynemouth smelter between May and September, (ii) which site/habitat hosts the highest diversity of flower visiting species, and (iii) what factors influence differences between sites/habitats. Answering these questions allows us to determine which habitats have the highest value for flower visitor biodiversity at present and which sites would benefit from management.

\section{Study Design}

Eight individual sites representing different habitat types were identified before the start of the study and the diversity of flower visiting insects was assessed within these sites on a monthly basis for one survey season (May-September).

2.1. Study Site. The study was conducted on land surrounding the Rio Tinto Alcan Aluminium smelter in Lynemouth, UK $\left(55.2016^{\circ} \mathrm{N}, 1.5396^{\circ} \mathrm{W}\right)$. Covering 82.7 hectares the site is typical of a working industrial site, with intensively managed grassland and shrub borders around offices, access roads, car parks, and production units. However, 20.7 hectares (25\%) of the site is predominately scrub, woodland, and wetland forming a buffer zone. To the west of the smelter, hybrid poplar trees have been mixed with native European tree species such as Sorbus aria (whitebeam), Acer pseudoplatanus (sycamore), and Quercus robur (oak) to create a fast growing screen to the smelter. Since this planting, the densely populated woodlands have left a bleak understory, dominated by two species of plant: the blackberry (Rubus fruticosus) and the nettle (Urtica dioica). Grassland which has been left unmanaged is becoming dominated by thistles (Cirsium sp.) and rank grasses which are restricting the growth of other species.

Insect flower visitors were sampled from eight sites around the smelter over the period of May-September 2011. The selected sites represented a range of habitats which include Flower Rich grassland (FR), Mown Grassland (MG), New Hedge $(\mathrm{NH})$, Old Hedge $(\mathrm{OH})$, Plantation Woodland $(\mathrm{Pl})$, Pond (Po), Ridge and Furrow Grassland (RF), and Woodhorn Woodland (WW). All eight sites were contiguous and covered a similar area; therefore patch size is unlikely to be influential (Table 1).

\subsection{Insect Sampling}

2.2.1. Pan Traps. Three pan traps $(17 \mathrm{~cm}$ diameter and $6 \mathrm{~cm}$ depth) were placed at each site, $1 \mathrm{~m}$ apart in a triangle formation. Blue, yellow, and white UV reflective plastic bowls were used to account for colour preference by certain insects [16]. These colours were used for three principal reasons; they 
represent a range of wavelengths found in the visual spectrum; they are similar to flower colours and have been proven to attract a variety of flower visiting species $[17,18]$. Traps were filled to the three-quarter line with water, to which several drops of unscented dishwashing detergent (Ecover Zero) were added to reduce the surface tension. Pan traps were set approximately $0.5 \mathrm{~m}$ above the ground at the height of the surrounding vegetation to allow the trap to be visible to flying insects. Wooden posts with brackets and wire were used to secure the pans in place during sampling.

Traps were exposed for a period of 30 hours (traps set at 10.00 and collected at 16.00 the following day) twice a month. On collection, the specimens were transferred into glass vials, labeled, and preserved in $70 \%$ ethanol. All flower visiting species shown to be important for pollination were identified to genus or family level using a dichotomous key. From the order Diptera, frequent flower visitors are concentrated in three main families: Syrphidae, Bombyliidae, and Tachinidae [19]. Families such as Empididae and Asilidae, known to frequent flowers for predatory reasons, were also collected. All other Diptera families were not included within this study.

2.2.2. Observation Plots. Data was collected from observation plots at each site to complement the pan trap data as it allowed the monitoring of species less represented within pan trap samples, such as Lepidoptera and Apidae [20]. Initially, net collecting along a transect was proposed; however due to the access restrictions within industrial areas and the topography of the land this method was considered inappropriate. Each observation plot measuring $1 \mathrm{~m}^{2}$ was surveyed twice each month during May, June, July, August, and September. Observations were made from a single point for a period of five minutes. Each insect seen to enter the observation plot was recorded; if the insect began to forage, the plant host was also recorded. Bumblebees and butterflies were identified to species, while hoverflies were identified to genus where possible. Due to the similarity between workers of $B$. terrestris and B. lucorum these species were treated as an aggregate species, as identification is unreliable in the field [21]. Observations were only initiated between 10:00 and 17:00 h, when weather conformed to Butterfly Monitoring Scheme standards [22].

2.3. Botanical Structure and Flower Density. Estimates of flower density were collected for each site twice monthly. Ten randomly placed $625 \mathrm{~cm}^{2}$ quadrats were used within the sample area (area surrounding the trio of pan traps). In each quadrat, the numbers of plants and the number of flower heads per plant species were recorded. The flower density was used as a surrogate measure for nectar availability as direct measurement of nectar parameters in the field is regarded as impractical [14].

2.4. Data Analysis. Data collected from the pan traps and the observation plots was combined to create one dataset. Minitab 16 was used to complete Correlation and ANOVA (Kruskal-Wallis) analysis on the total numbers of insects recorded for each habitat. Shannon Weiner diversity index was used to determine a diversity value for each habitat. This value was derived from species richness and relative abundance of each species and quantifies how well species are represented within a community. Diversity was then compared against month and flower density as individual factors. The statistical program R version 2.15.1 [23] was used to perform the Mantel test function within the "ade4" package [24]. This was conducted to determine whether the differences observed resulted from the factors studied or spatial differences.

As a result of the taxonomic variation between insect samples primary analysis has been conducted with four guilds of flower visiting insect: (1) nectar feeding, (2) parasitic insects, (3) pollen collecting, and (4) predatory insects. Where trends were indicated, further analysis using the detailed dataset was undertaken.

Due to the multispecies nature of the data and the survey design utilised in the study, multivariate analysis was utilised $[25,26]$. Insect assemblages within each habitat were compared using PRIMER 6.0, a nonparametric multivariate statistical package. Multidimensional scaling (MDS) plots based on Bray-Curtis similarity measures were used to compare insect assemblages. Similarity percentage (SIMPER) analysis was also run on the data matrix; SIMPER decomposes BrayCurtis similarities between all pairs of samples to identify those species that contribute most to the differences observed [26].

\section{Results}

Over the period May-September 2011, a total of 1138 individual insects were sampled across the four guilds, within the eight sites. A nested ANOSIM of sites within month showed there was no significant difference in the numbers of each flower visiting guild between sites $(R=0.054, P=0.265)$, but there was a significant difference between months $(R=0.387$, $P<0.001)$. The same trend was observed looking at insect assemblage for sites $(R=-0.063, P=0.268)$ and month $(R=$ $0.342, P<0.001)$. Despite the lack of significant differences between flower visiting insects between the sites, there were strong patterns noticeable within the dataset. A Mantel test showed that there was no spatial correlation between distance and insect diversity within this study $(r=0.093, P=0.65)$.

3.1. Response of Insect Assemblages to Site. The highest number of individuals was recorded within the Pond site $(n=$ 234) and the lowest within the Flower Rich Grassland ( $n=$ 67). Few insect families recorded were site specific; most species were recorded across all sites; however individuals from Satyridae, Panorpidae, Tipulidae, and Coccinellidae were in isolated populations. Tenthredinidae occurred in all sites except the Plantation Woodland. The most abundant families recorded were the Ichneumonidae $(n=264)$ and the Syrphidae $(n=375)$. Within the family Syrphidae, $47 \%$ of records were from a single species Episyrphus balteatus, with 176 individuals recorded across the survey period. Individuals from both families were present across all sites.

Removing month as a factor, average count data showed that the Old Hedge, Pond and Ridge and Furrow Grassland, had more individuals compared to the other sites 


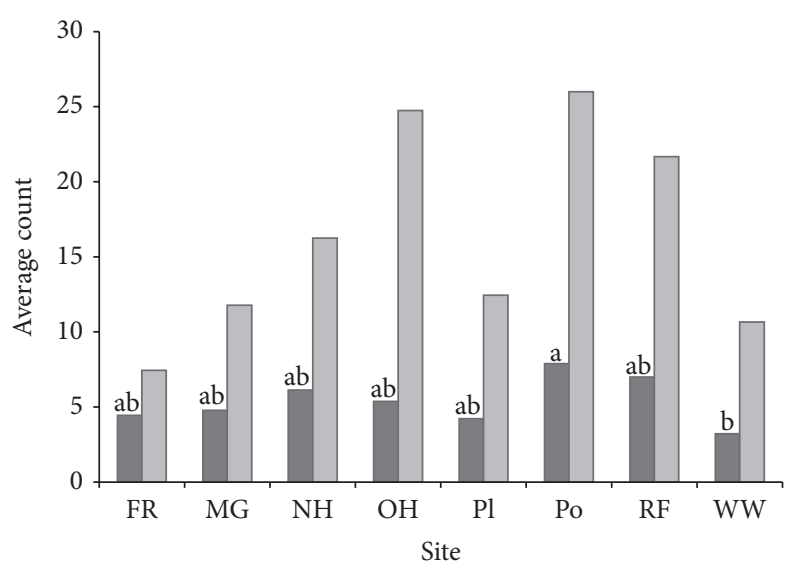

$S$

$N$

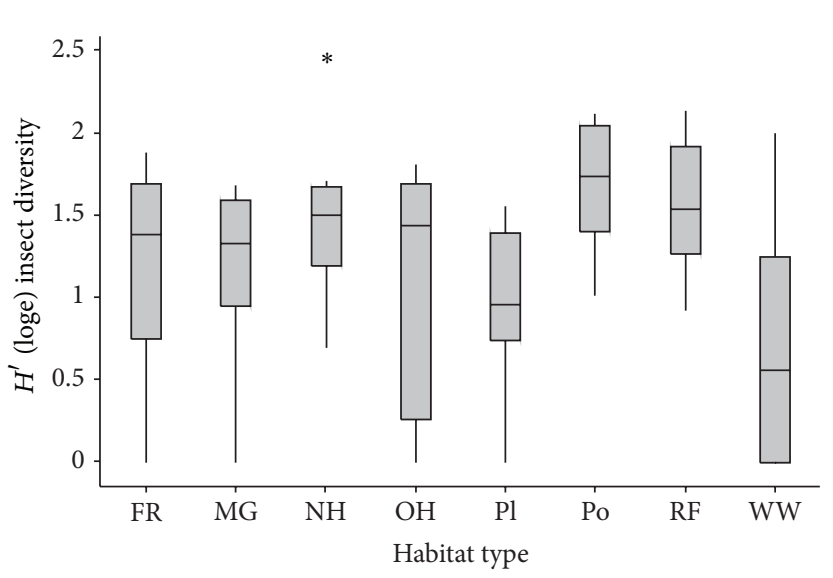

(b)

FIGURE 1: Response of insects to site. (a) Mean count for number of species $(S)$ and abundance $(N)$. Letters represent significant differences between sites following Tukey comparisons (b) Whiskered Box Plot showing the range of diversity scores. Box indicates median value and lower and upper quartiles. Whiskers indicate the range. Outliers indicated by an asterisk. Flower Rich Grassland (FR), Mown Grassland (MG), New Hedge $(\mathrm{NH})$, Old Hedge $(\mathrm{OH})$, Plantation Woodland (Pl), Pond (Po), Ridge (RF) and Furrow Grassland, and Woodhorn Woodland (WW).

(Figure 1(a)); however the difference was nonsignificant (Kruskal-Wallis $H=11.87, P=0.105$ ). When using the number of species/families recorded for each site there was a significant difference between sites (ANOVA, $F=2.43$, $P<0.05)$. Tukey comparisons revealed that the differences between Pond and Woodhorn Wood were the cause of this variation $(t=2.98, P<0.01)$ (Figure $1(\mathrm{a})$ ).

When looking at total diversity rather than abundance, a higher diversity of species was present in the sites; New Hedge, Pond and Ridge and Furrow (Figure 1(b)). This changes the result from the abundance data, whereby the Old Hedge was more important than the New Hedge. However, the data is highly variable between sample dates.

A significant difference in the diversity of flower visiting insects based on Shannon diversity scores was recorded across all sites (Kruskal-Wallis, $H=17.75, P<0.05$ ) (Figure 1(b)). Repeated Mann Whitney tests revealed that the Pond had a significantly higher species diversity compared to Mown Grassland, Plantation, and Woodhorn Wood. Woodhorn Wood had significantly lower species diversity than Mown Grassland, Pond and Ridge and Furrow (Figure 5).

Bray Curtis Similarity analysis highlighted similarities between sites driven by the guilds (Figure 2(a)). Parasitic insects were found in high numbers within all sites; however, they did not occur in all replicate samples (Figures $2(a)$, 2(b), 6, and 7). There was a higher dominance of parasitic insects recorded within Plantation and Woodhorn Woodland indicating the importance of a woodland environment for this guild. The families Ichneumonidae and Tenthredinidae behave in a similar manner with records across all sites; however in contrast to Ichneumonidae, Tenthredinidae was underrepresented within the woodland sites (Figure 7).

The pollen collecting, nectar feeding, and predatory insect guilds were also present throughout all habitats. The pollen collecting guild saw a marked reduction in numbers within the Plantation and Old Hedgerow sites, whereas the other guilds were in higher abundance (Figure 6). This difference appeared to be influenced by two Bombus species (B. lapidarius and B. lucorum/terrestris) which were found in similar abundances throughout all sites; however larger numbers were recorded in the Flower Rich site for $B$. lapidarius and the New Hedge for B. lucorum/terrestris. There was no record of $B$. lucorum/terrestris within the Old Hedge (Figure 7).

The nectar feeding guild was also influenced heavily by species within the family Pieridae including Anthocharis cardamines, Pieris napi, and P. brassicae which were observed across six of the eight sites, yet were more dominant within the Pond site (Figure 7).

3.2. Response of Insect Assemblage to Month Surveyed. The numbers within each flower visiting guild were significantly different between months (ANOSIM, $R=0.387, P<0.001$ ), with the dominance of each guild affected (Figure 2). Furthermore, insect assemblages were also significantly different between months (ANOSIM, $R=0.342, P=0.001$ ), with pairwise comparisons indicating that all months were significantly different to each other with regard to insect assemblage except for the months of May and June (Figure 8).

The parasitic insect guild dominated throughout the entire survey season (Figures 2(c), 9, and 10). Higher numbers of this guild were recorded in May but reduced through the survey season with a marked reduction in September. Ichneumonidae and Tenthredinidae appear to be the most influential families for this trend (Figure 10). The nectar feeding guild also showed significant seasonal changes in abundance; however, the trend was directly opposite to that of the parasitic guild, with records increasing over the survey season 


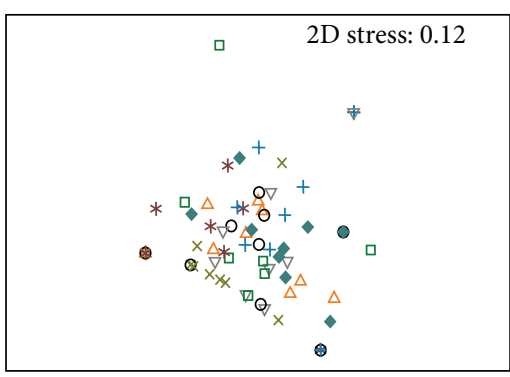

$\begin{array}{ll}\triangle \mathrm{RF} & \circ \mathrm{MG} \\ \times \mathrm{Pl} & +\mathrm{FR} \\ * \mathrm{WW} & \square \mathrm{OH} \\ \diamond \mathrm{Po} & \nabla \mathrm{NH}\end{array}$

(a)

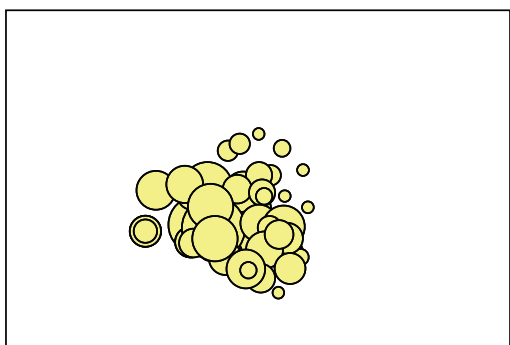

(c) Parasitic insects
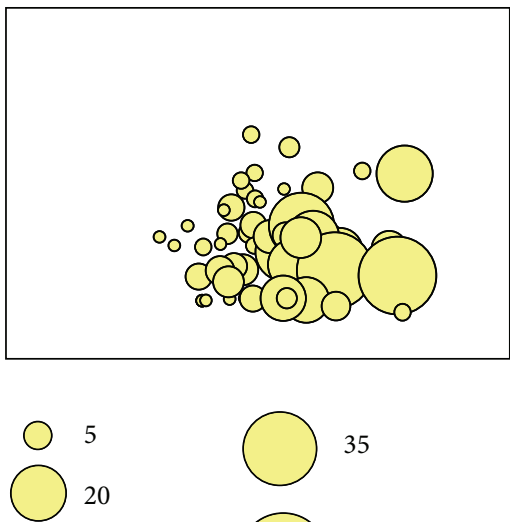

35

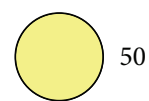

(e) Nectar feeding

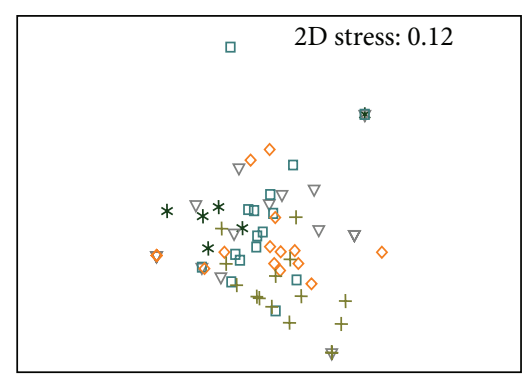

$$
\begin{array}{ll}
\nabla \text { June } & + \text { September } \\
\square \text { July } & * \text { May } \\
\diamond \text { August } &
\end{array}
$$

(b)

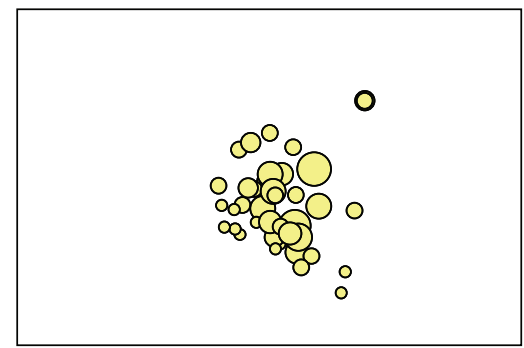

(d) Pollen collecting
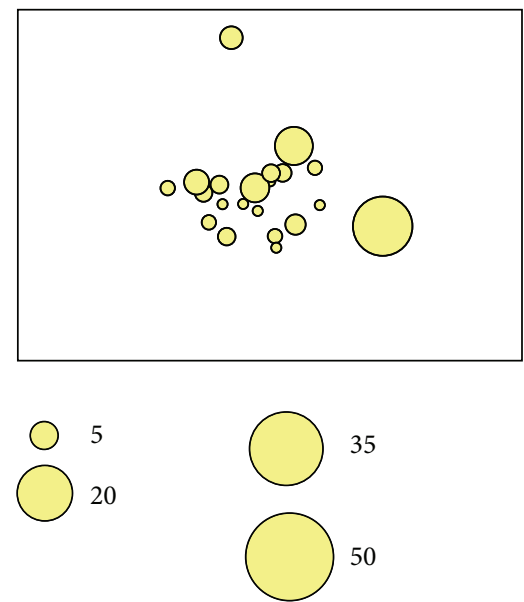

(f) Predatory insects

FIGURE 2: (a) Multidimensional Scaling (MDS) plot of flower visiting guilds at each of the eight sites based on Bray-Curtis similarity. (b) MDS plot of flower visiting guilds at each of the five sampling month based on Bray-Curtis similarity. ((c)-(f)) Bubble plot overlaid on the MDS sample points indicating patterns driven by the abundance of each guild. These highlight the role of each guild in shaping the community, bubble size relative to the number of individuals at that point.

with a peak in September (Figure 9). This trend was clearly influenced by late feeding Syrphidae present during this month (Figure 10).

3.3. Response of Insect Assemblages to Flower Density. Mean flower density across the site ranged between 0 and 17.6 per $\mathrm{m}^{2}$ over the season. Only one site had no flowering plants recorded and this was in the plantation (Figure 3(a)). Flowering plants were available across all other sites during July and August, yet by September half of the eight sites $(\mathrm{NH}$,
$\mathrm{Pl}, \mathrm{RF}$, and $\mathrm{WW}$ ) had no flowering plants available to insects (Figure 3(b)). The Flower Rich site was the only one to have flowering plants available all season (Figure 3(b)), although surprisingly this site had the lowest recorded insect visitation. By contrast, the pond had the largest insect assemblages, but no flowers available within the month of May.

Following an ANOSIM on flower visiting guilds an influence of flower density was observed but not significant $(R=0.14, P=0.06)$. However, when the whole data set was analysed flower density was highlighted as a significant factor 


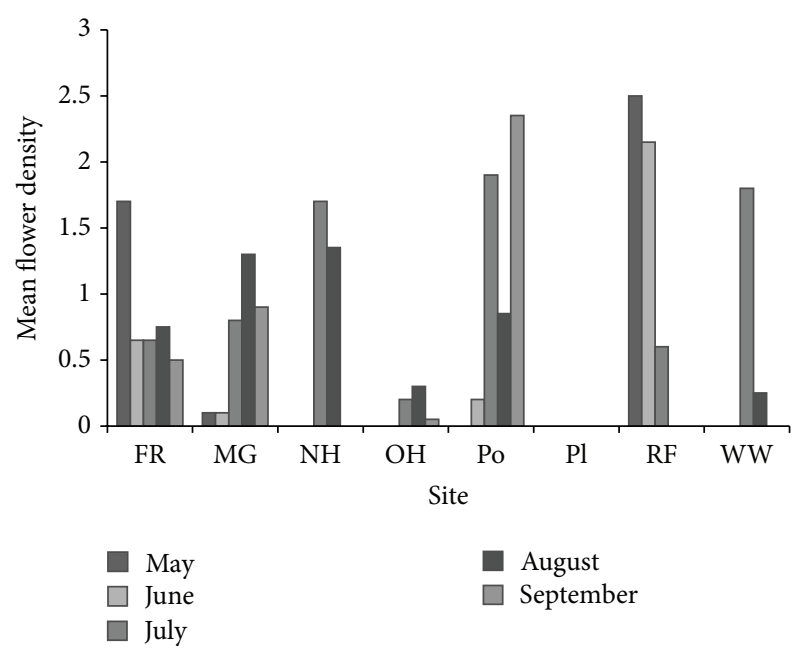

(a)

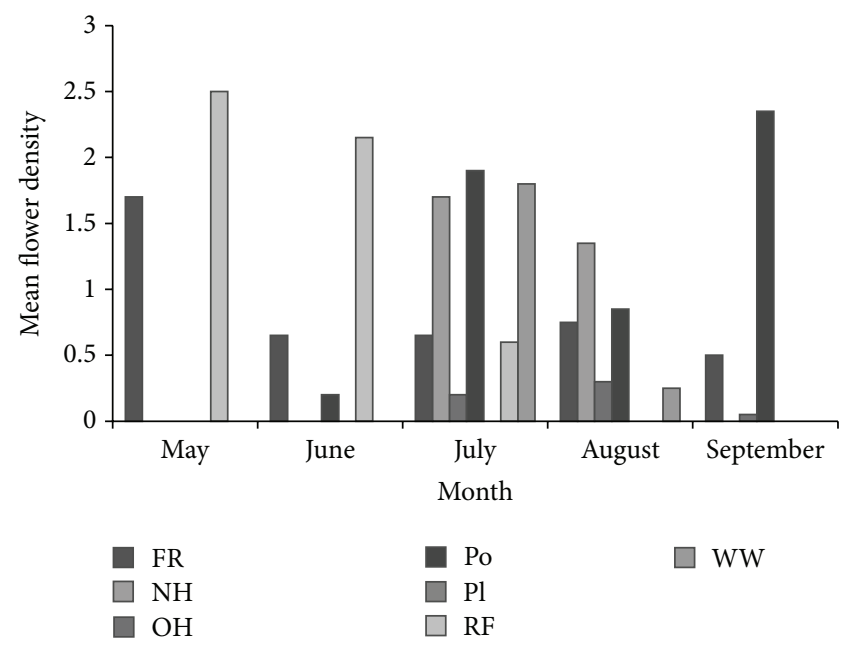

(b)

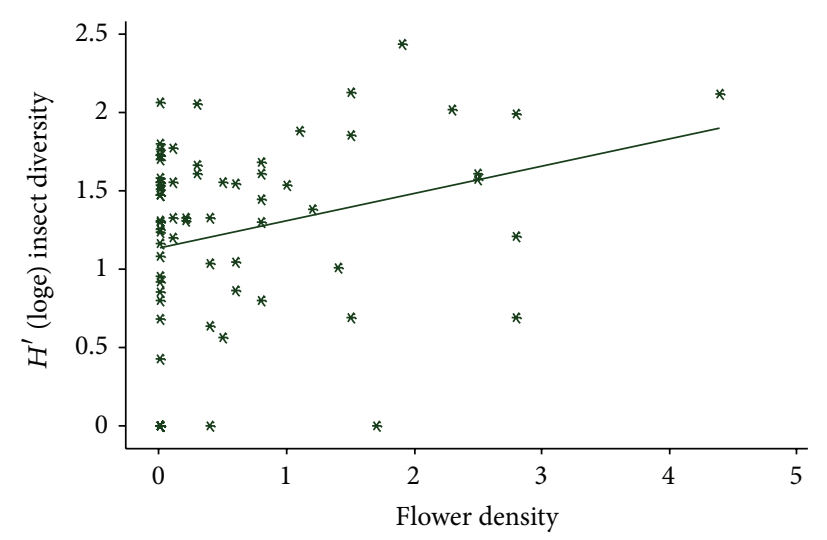

(c)

FIGURE 3: Floral resource across the sites: (a) mean flower density for each site subcategorised by month (b). Mean flower density for each month subcategorised by site, (c) Scatterplot with line of best fit showing the correlation between flower density and Shannon Weiner diversity score for insects. Flower rich (FR), Mown grassland (MG), New Hedge (NH), Old hedge (OH), Plantation (Pl), Pond (Po), Ridge and Furrow (RF), and Woodhorn Woodland (WW).

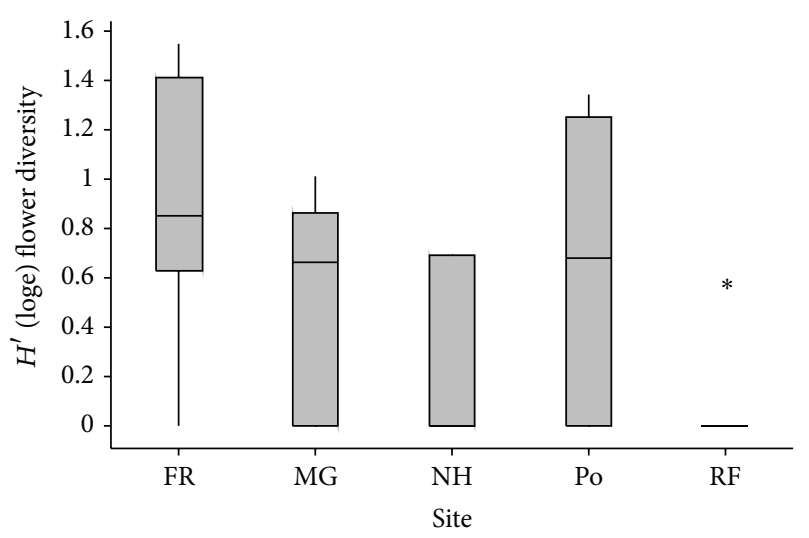

(a)

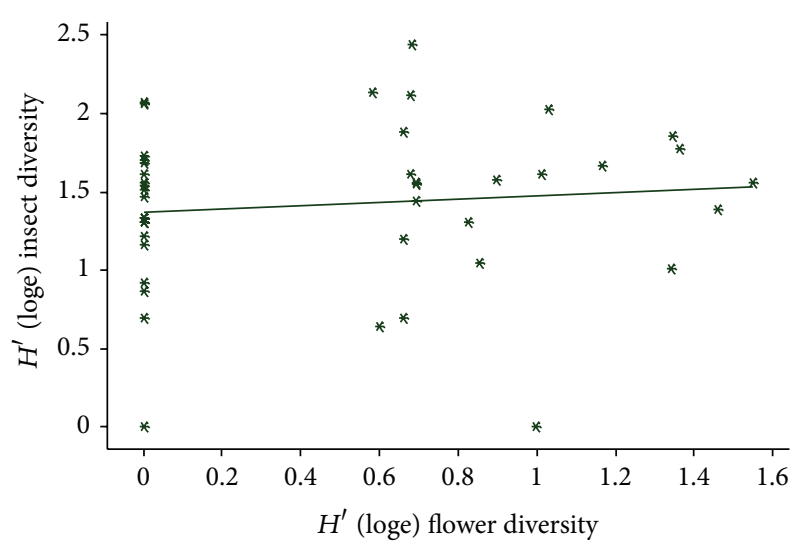

(b)

Figure 4: (a) Whiskered Box Plot showing the range of diversity scores. Box indicates median value, lower, and upper quartiles. Whiskers indicate the range. Outliers indicated by an asterisk. Flower Rich Grassland (FR), Mown Grassland (MG), New Hedge (NH), Pond (Po), and Ridge and Furrow Grassland (RF). (b) Scatterplot with line of best fit showing the correlation between shannon Weiner diversity score for insects and flowers. 


\begin{tabular}{|c|c|c|c|c|c|c|c|c|}
\hline Site & FR & MG & $\mathrm{NH}$ & $\mathrm{OH}$ & $\mathrm{Pl}$ & Po & $\mathrm{RF}$ & WW \\
\hline FR & & 1a & $0.665 a$ & $0.961 \mathrm{a}$ & $0.269 \mathrm{a}$ & $0.077 \mathrm{a}$ & $0.289 a$ & $0.12 \mathrm{a}$ \\
\hline MG & & & $0.736 \mathrm{a}$ & $0.923 a$ & $0.145 \mathrm{a}$ & $0.038 b$ & $0.289 a$ & $0.0835 a$ \\
\hline $\mathrm{NH}$ & & & & $0.713 \mathrm{a}$ & $0.075 \mathrm{a}$ & $0.229 a$ & $0.665 \mathrm{a}$ & $0.0234 b$ \\
\hline $\mathrm{OH}$ & & & & & $0.267 \mathrm{a}$ & $0.0829 a$ & $0.36 a$ & $0.2233 a$ \\
\hline $\mathrm{Pl}$ & & & & & & $0.0047 \mathrm{c}$ & $0.0171 b$ & $0.23 a$ \\
\hline Po & & & & & & & $0.536 \mathrm{a}$ & $0.0046 c$ \\
\hline $\mathrm{RF}$ & & & & & & & & $0.0103 b$ \\
\hline WW & & & & & & & & \\
\hline
\end{tabular}

Figure 5: Comparison of Mann Whitney Statistical test $P$ value results for Shannon diversity score between sites. Significant differences are highlighted in bold, and differences in significance threshold are highlighted by a different letter. Flower Rich Grassland (FR), Mown Grassland $(\mathrm{MG})$, New Hedge $(\mathrm{NH})$, Old Hedge $(\mathrm{OH})$, Plantation Woodland (Pl), Pond (Po), Ridge and Furrow Grassland (RF), and Woodhorn Woodland (WW).

\begin{tabular}{|l|l|l|l|l|l|l|l|l|}
\hline Insect guild & FR & MG & NH & OH & Pl & Po & RF & WW \\
\hline Nectar feeding & 3.86 & 5.27 & 5.57 & 5.26 & 4.53 & 6.15 & 5.23 & 3.2 \\
\hline Parasitic insects & 3.85 & 5.73 & 5.41 & 4.86 & 7.67 & 4.35 & 6.03 & 7.25 \\
\hline Pollen collecting & 6.28 & 2.98 & 3.31 & 0.9 & 0.35 & 4.16 & 3.2 & 1.93 \\
\hline Predatory insects & 0.41 & 0.77 & 1.06 & 3.93 & 1.21 & 1.2 & 1.05 & 1.7 \\
\hline
\end{tabular}

\begin{tabular}{|l|l|l|l|l|l|l|l|l|}
\hline Key \% & $0.00-1.00$ & $1.01-2.00$ & $2.01-3.00$ & $3.01-4.00$ & $4.01-5.00$ & $5.01-6.00$ & $6.01-7.00$ \\
\hline
\end{tabular}

FIGURE 6: Heatmap-table summarising the relative abundance (\%) of insect guild within each site, based on SIMPER analysis of count data recorded during the survey period. (FR) Flower Rich Grassland, Mown Grassland (MG), New Hedge (NH), Old Hedge (OH), Plantation Woodland (Pl), Pond (Po), Ridge and Furrow Grassland (RF), and Woodhorn Woodland (WW).

\begin{tabular}{|l|c|c|c|c|c|c|c|c|}
\hline & FR & MG & NH & OH & Pl & Po & RF & WW \\
\hline Icheumonidae & 2.27 & 4.4 & 3.12 & 3.98 & 6.54 & 2.71 & 3.87 & 7.18 \\
\hline Tenthredinidae & 0.89 & 1.25 & 1.41 & 0.73 & 0 & 2.29 & 3.42 & 0.31 \\
\hline Episyrphus sp. & 0.3 & 1.31 & 1.99 & 3.08 & 1.28 & 2.96 & 2.38 & 1.68 \\
\hline Chalcidoidea & 1.02 & 0.9 & 1.44 & 1.55 & 0.84 & 0.83 & 1.43 & 2.36 \\
\hline Syrphus sp. & 0.71 & 0.41 & 1.31 & 1.99 & 1.5 & 1.38 & 0.91 & 0.45 \\
\hline Platycheirus sp. & 0.99 & 0 & 1.01 & 1.6 & 1.1 & 0.41 & 0.92 & 0 \\
\hline Bombus lapidarius & 4.77 & 1.44 & 0.8 & 0.46 & 0.24 & 1.3 & 1.61 & 0.38 \\
\hline Bombus lucorum/ terrestris & 1.12 & 0.45 & 2.47 & 0 & 0.24 & 1.99 & 1.59 & 1.25 \\
\hline Asilidae & 0.34 & 0.75 & 0.98 & 3.59 & 1.03 & 0.65 & 0.63 & 1.93 \\
\hline Empididae & 0 & 0 & 0.25 & 0.29 & 0.53 & 0.78 & 0.67 & 0 \\
\hline Eupeodes sp. & 0 & 1.03 & 0.87 & 1.69 & 0 & 0.51 & 0.93 & 0 \\
\hline Melanostoma sp. & 0.28 & 0 & 0 & 0.19 & 0.8 & 0.17 & 0.16 & 0.31 \\
\hline Noctuidae & 1.24 & 0 & 0.42 & 0 & 0.37 & 0.33 & 0.6 & 0 \\
\hline Coccinellidae & 0.74 & 0 & 0 & 0 & 0 & 0 & 0.75 & 0 \\
\hline Hesperiidae & 0.32 & 0 & 0 & 0 & 0 & 0.53 & 0.69 & 0 \\
\hline Megachilidae & 0.74 & 1.49 & 1.18 & 0.29 & 0 & 0.21 & 0.51 & 0 \\
\hline Apis mellifera & 0.6 & 0 & 0 & 0 & 0 & 0 & 0.31 & 0.31 \\
\hline Bombus pascuorum & 0.32 & 0.24 & 0 & 0.25 & 0 & 1.53 & 0 & 0.9 \\
\hline Vespidae & 0.3 & 0.73 & 0.45 & 0 & 0.24 & 0.72 & 0 & 0.45 \\
\hline Pieridae & 0.24 & 0.64 & 1.03 & 0.36 & 0.24 & 2.19 & 0 & 0 \\
\hline Helophilus sp. & 0.43 & 0.71 & 0.66 & 0 & 0 & 1.27 & 0.37 & 0 \\
\hline Epistrophe sp. & 0 & 0 & 0 & 0 & 0 & 0.57 & 0 & 0 \\
\hline Eristalis sp. & 1.33 & 0.79 & 0.29 & 0 & 0 & 0.44 & 0.16 & 0 \\
\hline Sphaerophoria sp. & 0 & 0 & 0.34 & 0 & 0 & 0 & 0.33 & 0 \\
\hline Satyridae & 0 & 0 & 0.47 & 0 & 0 & 0 & 0 & 0 \\
\hline Panorpidae & 0 & 0 & 0.42 & 0.34 & 0 & 0 & 0 & 0 \\
\hline
\end{tabular}

\section{\begin{tabular}{|l|l|l|l|l|l|l|l|l|l|l|}
\hline Key $\%$ & 0 & $0.01-1.00$ & $1.01-2.00$ & $2.01-3.00$ & $3.01-4.00$ & $4.01-5.00$ & $5.01-6.00$ & $6.01-7.00$ & 7.01
\end{tabular}}

FIGURE 7: Heatmap-table summarising the relative abundance (\%) of dominant taxon within each site, based on SIMPER analysis of count data recorded during the survey period. 


\begin{tabular}{|c|c|c|c|c|c|}
\hline Month & May & June & July & Aug & Sept \\
\hline May & & $0.086 a$ & $0.014 b$ & $0.015 b$ & $0.004 c$ \\
\hline June & & & $0.002 c$ & $0.003 c$ & $0.001 \mathrm{c}$ \\
\hline July & & & & $0.001 c$ & $0.001 c$ \\
\hline Aug & & & & & $0.006 c$ \\
\hline Sept & & & & & \\
\hline
\end{tabular}

FIGURE 8: Summary of $P$-value results for Pairwise comparisons of insect assemblages between Months. Significant differences are highlighted in bold, and differences in significance threshold are highlighted by a different letter.

\begin{tabular}{|c|c|c|c|c|c|}
\hline Insect guild & May & June & July & August & September \\
\hline Parasitic insects & 7.07 & 5.24 & 5.95 & 6.31 & 4.4 \\
\hline Pollen collecting & 2.72 & 3.98 & 3.28 & 3.23 & 1.47 \\
\hline Nectar feeding & 2.24 & 3.88 & 4.41 & 4.7 & 7.76 \\
\hline Predatory insects & 2.98 & 1.34 & 1.98 & 0.83 & 0.5 \\
\hline
\end{tabular}

\begin{tabular}{|l|l|l|l|l|l|l|l|l|}
\hline Key \% & $0.00-1.00$ & $1.01-2.00$ & $2.01-3.00$ & $3.01-4.00$ & $4.01-5.00$ & $5.01-6.00$ & $6.01-7.00$ \\
\hline
\end{tabular}

FIGURE 9: Heatmap-table summarising the relative abundance (\%) of dominant guilds for each month, based on SIMPER analysis of count data recorded during the survey period.

\begin{tabular}{|l|c|c|c|c|c|}
\hline & May & June & July & Aug & Sept \\
\hline Icheumonidae & 6.23 & 4.05 & 4.64 & 4.07 & 2.87 \\
\hline Bombus lapidarius & 2.07 & 1.45 & 1.44 & 1.71 & 1.2 \\
\hline Asilidae & 2.21 & 1.01 & 1.89 & 0.68 & 0.46 \\
\hline Bombus lucorum / terrestris & 0.48 & 2.26 & 1.33 & 0.96 & 0.34 \\
\hline Tenthredinidae & 1.77 & 1.2 & 1.08 & 2.07 & 0.71 \\
\hline Empididae & 1.51 & 0.36 & 0.19 & 0.14 & 0.13 \\
\hline Chalcidoidea & 0.48 & 0.99 & 1.19 & 1.51 & 1.53 \\
\hline Pieridae & 0.93 & 0.49 & 1.16 & 0.35 & 0.3 \\
\hline Megachilidae & 0.4 & 0.85 & 0.92 & 0.62 & 0 \\
\hline Nymphalidae & 0.91 & 0.32 & 0.16 & 0 & 0 \\
\hline Coccinellidae & 0 & 0.96 & 0 & 0 & 0 \\
\hline Noctuidae & 0 & 0.83 & 0.4 & 0.15 & 0.43 \\
\hline Melanostoma sp. & 0.57 & 0 & 0.12 & 0.27 & 0.44 \\
\hline Helophilus sp. & 0 & 0.53 & 0 & 0.16 & 1.37 \\
\hline Panorpidae & 0 & 0.41 & 0 & 0 & 0 \\
\hline Vespidae & 0 & 0.32 & 0.46 & 0.38 & 0.47 \\
\hline Chrysididae & 0 & 0.32 & 0.19 & 0 & 0 \\
\hline Hesperiidae & 0 & 0.18 & 0.69 & 0 & 0 \\
\hline Bombus pascuorum & 0 & 0.25 & 0.73 & 0.74 & 0 \\
\hline Syrphus sp. & 0 & 0.32 & 0.88 & 1.19 & 2.31 \\
\hline Episyrphus sp. & 0 & 0.32 & 1.74 & 2.73 & 3.08 \\
\hline Apis mellifera & 0 & 0.35 & 0.34 & 0 & 0 \\
\hline Eupeodes sp. & 0 & 0.17 & 0.11 & 1.3 & 1.1 \\
\hline Platycheirus sp. & 0 & 0.24 & 0.11 & 0.82 & 2.17 \\
\hline Eristalis sp. & 0 & 0.17 & 0 & 0.48 & 1.22 \\
\hline & & & & & \\
\hline
\end{tabular}

\begin{tabular}{|l|l|l|l|l|l|l|l|l|l|l|}
\hline Key $\%$ & 0 & $0.01-1.00$ & $1.01-2.00$ & $2.01-3.00$ & $3.01-4.00$ & $4.01-5.00$ & $5.01-6.00$ & 6.0 \\
\hline
\end{tabular}

FIGURE 10: Heatmap-table summarising the relative abundance (\%) of dominant taxon for each month, based on SIMPER analysis of count data recorded during the survey period. 


\begin{tabular}{|c|c|c|c|c|c|}
\hline Site & FR & MG & $\mathrm{NH}$ & Po & RF \\
\hline FR & & $0.1971 \mathrm{a}$ & $0.0387 b$ & $0.3722 \mathrm{a}$ & $0.001 \mathrm{~d}$ \\
\hline MG & & & $0.2212 \mathrm{a}$ & $0.585 a$ & $0.012 c$ \\
\hline $\mathrm{NH}$ & & & & $0.2736 a$ & $0.1741 \mathrm{a}$ \\
\hline Po & & & & & $0.0354 b$ \\
\hline RF & & & & & \\
\hline
\end{tabular}

FIgure 11: Comparison of Mann-Whitney Statistical test $P$ value results for Shannon diversity score (flower diversity) between sites. Significant differences are highlighted in bold, and differences in significance threshold are highlighted by a different letter.

with regard to insect assemblage (ANOSIM, $R=0.233, P<$ 0.01 ). Although flower density was not significantly different between months (Kruskal-Wallis, $H=8.68, P=0.070$ ), insect assemblages were significantly affected by flower density when nested within month (ANOSIM, $R=0.178, P<$ $0.01)$. Analysis of the entire data set also highlighted a significant correlation $(\rho=0.245, P<0.01)$ between Shannon Wiener Diversity of insects and flower density (Figure 3(c)).

3.4. Response of Insect Assemblages to Flower Diversity. The Shannon Wiener diversity of flowering plants observed within each site was calculated. Three of the eight sites $(\mathrm{OH}$, $\mathrm{WW}$, and $\mathrm{Pl}$ ) had diversity scores of zero and therefore have been omitted from further analysis. The Flower Rich site had the highest recorded diversity (Figure 4), and a significant difference was observed between sites (Kruskal-Wallis $H=$ 13.37, $P<0.01$ ). Repeated Mann-Whitney tests highlighted which sites saw the greatest differences (Figure 11). The Flower Rich and Ridge and Furrow Grasslands were the greatest drivers for this result. Flower diversity was not identified as a significant factor for flower visiting guild assemblage (ANOSIM, $R=-0.082, P=0.824$ ) and there was no correlation of flower diversity with insect diversity $(\rho=0.162$, $P=0.298)$.

\section{Discussion}

Kunin [13] highlighted that many habitat types should be incorporated within a reserve area to capture the species variation caused by habitat discontinuities, suggesting that more habitat types are generally better than one to enhance biodiversity. This study, however, shows that flower visiting insects recorded at the Lynemouth Smelter site were influenced predominantly by the flower density, rather than the distinct sites/habitats themselves, a finding which is widely supported [14, 15, 27]. Although, site/habitat type was not a significant factor in insect assemblage within this study, flower density was, suggesting that varied botanical structure and the presence of certain flowering plants such as Centaurea nigra (common knapweed) and Heracleum sphondylium (common hogweed) are more important than the number of different types of habitats specifically. Conversely, within this study, flower diversity did not impact the insect assemblage. This could be a result of the low numbers of flower species recorded, as flower diversity is indeed an important factor in determining flower visitor presence $[14,28]$. The type of flowerhead available to insects will determine which species feed, hunt, and breed within a particular habitat $[29,30]$. Ideally, a variety of host plants for larvae and immature insects are required [31-33]. Furthermore, flower longevity and nectar resource have previously been shown to have an effect on the insect community within habitats [34,35].

As expected, month had a significant effect on insect assemblages, again complementing results seen in previous studies $[36,37]$. Certain taxa were present at different times of the year, likely due to variation in emergence and breeding periods as a result of an insect's dependence on factors such as weather, as well as the availability of host and food plants for different insects groups. Only one of the eight sites had plants flowering for the entire survey period (the Flower Rich site); however due to regular mowing of this area the flower density was low, resulting in this area having the lowest recorded insect visitation. Nevertheless, insects were recorded across the whole season suggesting that this was not the only factor affecting the site's attractiveness. For example, the pan traps could have been less attractive to the foraging insects than the flowers present, resulting in the catch being proportional to the flower density as suggested by [38]. Additionally, despite a relatively high diversity of plant species within the Flower Rich site, it was dominated by one particular flower species, Lotus corniculatus (bird's foot trefoil). L. corniculatus was predominantly foraged by one particular species of pollinating insect, Bombus lapidarius, a species known to have a preference for yellow flowers and the appropriate mouth parts to access the nectar from this flower [30]. This dominance of the site by one flower species could in part explain the low insect visitation rates recorded in this particular study. L. corniculatus may not have been an appropriate flower resource for other insect species. Therefore, improving diversity of flowering plants within certain preexisting habitats will undoubtedly have a significant effect on the pollinating species present within the sites. Alternatively, there may have been other factors such as noise pollution and forage distance to consider which were not assessed during this study.

The number and diversity of insects could be influenced by improvements to the assessed sites, not only diversifying the flowering species available for forage, but also increasing diversity with regard to flower head shape. Ensuring a variety of flower heads such as umbels or composite heads will increase the number of flower visiting insects [39]. For example, low abundance of the hoverfly Episyprhus balteatus was recorded within the Flower Rich habitat, where hoverflies would normally be expected [40]. The dominant flower, $L$. corniculatus, is not preferred by hoverfly species as their mouthparts do not allow access to the nectar. By contrast larger numbers of hoverflies were observed within the Ridge and Furrow Grassland, Old Hedge, and Pond sites as a result of the flowering species present: umbelled flowers such as Oenanthe crocata (dropwort water hemlock) and Heracleum sphondylium (hogweed) and simple flowering species such as Crataegus monogyna (hawthorn). A reduction in the mowing frequency at the Flower Rich site may diversify the flowering species present, allowing species which are less hardy to germinate from the seedbank [41]. Furthermore, a study by López-Mariño et al. [42] also highlights, that due to the high 
proportion of perennial grasses often present within semiimproved habitats, only half the species stored within grassland's natural seedbank are present above the soil surface. This suggests that the sward can be diversified by managing the grass species present, proving a beneficial management strategy to enhance insect diversity for this site.

The Pond site had the largest insect assemblages, despite the limited floral resource available within the month of May. Some insect species are locating nest sites around this time, particularly bumblebees which start searching around April and peak in May [43]. Ensuring flowering plants are available throughout April to September is therefore an important management strategy, particularly for insect diversity. The availability of nest and forage sites is essential to pollinating insects and improvement in this area would likely have a positive effect on the overall insect diversity of this site [44, 45]. Conversely, there are few species of plant which flower early, therefore improvement to surrounding hedgerows, or planting of species such as Salix cinera and Malus sp. complemented with Laminum album and Glechoma hederacea could be more beneficial to the communities around the Lynemouth smelter [46].

Interestingly, this study highlights the importance of the method in which data sets are analysed, which could result in different interpretation of the data and therefore have a serious impact on the proposed management of a particular site. Firstly, the data was organised into guilds of insects to minimise taxonomic variation between data samples. The trends reported in this study were mirrored in both the guild analysis and complete taxon analysis showing that many of the results reported hold fast when analysing the data in different ways. However, some trends were weaker when looking at guilds, rather than when analysis was completed on the whole data set, which means significant findings could be overlooked if only one type of analysis was utilised. Furthermore, the data in this study showed that two sites, the Plantation and Woodhorn Woodland, had lower mean insect abundance, species richness, and Shannon Weiner diversity score than all the other surveyed sites, suggesting these two sites may not be that important for the flower visiting insect communities (although these differences were not all significant). However, when comparing insect assemblages these habitats were highlighted as important for parasitic insects such as Ichneumonidae. Following the initial analysis comparing mean averages of insect abundance per site, the importance of these habitats could have been overlooked and the site managed inappropriately for the dominant inhabitants. Until the community analysis was performed the dominance of Ichneumonidae and influence on the community may not have been appreciated, highlighting that community analysis is invaluable within biodiversity assessment. Secondly, with regard to Shannon Weiner diversity, a higher diversity of species was found to be present in three particular sites; the New Hedge, the Pond and the Ridge and Furrow Grassland. By contrast when looking at the abundance data, the Old Hedge is a more important site for insect assemblages than the New Hedge highlighted in the diversity data set.

The methods of analysis used in this study highlight the importance of data interpretation before management action plans are devised. The two variations in interpretation of the results, highlighted above, were both made with the same original data set; however, one utilised abundance data whilst the other used total diversity. The differences are likely caused as the diversity index takes into account both species richness and the relative abundance of each species to quantify how well species are represented within a community. Many management plans and advice provided to site managers contain information collected in a similar manner to this study to achieve specific objectives. Whether these objectives are to maximise species diversity or simply abundance, we recommend that the community interactions are assessed before management plans are drawn up to avoid the potential loss of valuable habitats and species through inappropriate management.

\section{Conclusion}

In conclusion, this study highlights the importance of data interpretation to determine management objectives and recommends analysing the community structure and identifying the dominant species prior to undertaking any land management. Although no significant difference was found between flower visiting insect diversity at sites when month was taken into account, flower density was highlighted as a factor driving the insect diversity. This result highlights that increasing the number of flowering plants rather than increasing the amount of specific habitats is a more costeffective management tool for industrial sites. Although, sites such as Flower Rich Grassland, would be expected to attract the highest diversity of flower visiting insects, this was not observed in the case of this study. This is likely a result of the high dominance of one particular species of flower, $L$. corniculatus, which may exclude certain insect assemblages. Importantly, this study highlights that with relatively low cost industrial sites such as the Lynemouth smelter could be improved with regard to insect diversity. This can be achieved by specific seed planting or a refinement of the mowing practices to allow diversification of flora within and between the sites, ultimately improving the overall ecological value of industrial areas.

\section{References}

[1] O. E. Sala, F. S. Chapin, J. J. Armesto et al., "Global biodiversity scenarios for the year 2100," Science, vol. 287, no. 5459, pp. 17701774, 2000.

[2] J. Krauss, R. Bommarco, M. Guardiola et al., "Habitat fragmentation causes immediate and time-delayed biodiversity loss at different trophic levels," Ecology Letters, vol. 13, no. 5, pp. 597605, 2010.

[3] B. S. Law and C. R. Dickman, "The use of habitat mosaics by terrestrial vertebrate fauna: implications for conservation and management," Biodiversity and Conservation, vol. 7, no. 3, pp. 323-333, 1998.

[4] S. D. Wratten, M. Gillespie, A. Decourtye, E. Mader, and N. Desneux, "Pollinator habitat enhancement: benefits to other ecosystem services," Agriculture, Ecosystems \& Environment, vol. 159, pp. 112-122, 2012. 
[5] J. Feehan, D. A. Gillmor, and N. Culleton, "Effects of an agrienvironment scheme on farmland biodiversity in Ireland," Agriculture, Ecosystems and Environment, vol. 107, no. 2-3, pp. 275286, 2005.

[6] M. J. Whittingham, "Will agri-environment schemes deliver substantial biodiversity gain, and if not why not?" Journal of Applied Ecology, vol. 44, no. 1, pp. 1-5, 2007.

[7] R. E. Kenward, M. J. Whittingham, S. Arampatzis et al., "Identifying governance strategies that effectively support ecosystem services, resource sustainability, and biodiversity," Proceedings of the National Academy of Sciences of the United States of America, vol. 108, no. 13, pp. 5308-5312, 2011.

[8] K. J. Gaston, R. M. Smith, K. Thompson, and P. H. Warren, "Urban domestic gardens (II): experimental tests of methods for increasing biodiversity," Biodiversity and Conservation, vol. 14, no. 2, pp. 395-413, 2005.

[9] M. A. Goddard, A. J. Dougill, and T. G. Benton, "Scaling up from gardens: biodiversity conservation in urban environments," Trends in Ecology and Evolution, vol. 25, no. 2, pp. 90-98, 2010.

[10] R. W. F. Cameron, T. Blanuša, J. E. Taylor et al., "The domestic garden-its contribution to urban green infrastructure," Urban Forestry \& Urban Greening, vol. 11, pp. 129-137, 2012.

[11] T. G. Benton, J. A. Vickery, and J. D. Wilson, "Farmland biodiversity: is habitat heterogeneity the key?" Trends in Ecology and Evolution, vol. 18, no. 4, pp. 182-188, 2003.

[12] T. Tscharntke, I. Steffan-Dewenter, A. Kruess, and C. Thies, "Characteristics of insect populations on habitat fragments: a mini review," Ecological Research, vol. 17, no. 2, pp. 229-239, 2002.

[13] W. E. Kunin, "Sample shape, spatial scale and species counts: implications for reserve design," Biological Conservation, vol. 82, no. 3, pp. 369-377, 1997.

[14] S. G. Potts, B. Vulliamy, A. Dafni, G. Neeman, and P. Willmer, "Linking bees and flowers: how do floral communities structure pollinator communities?” Ecology, vol. 84, no. 10, pp. 26282642, 2003.

[15] J. Ghazoul, "Floral diversity and the facilitation of pollination," Journal of Ecology, vol. 94, no. 2, pp. 295-304, 2006.

[16] J. S. Wilson, T. Griswold, and O. J. Messinger, "Sampling bee communities (Hymenoptera: Apiformes) in a desert landscape: are pan traps sufficient?" Journal of the Kansas Entomological Society, vol. 81, no. 3, pp. 288-300, 2008.

[17] D. Moroń, H. Szentgyörgyi, M. Wantuch et al., "Diversity of wild bees in wet meadows: implications for conservation," Wetlands, vol. 28, no. 4, pp. 975-983, 2008.

[18] C. Westphal, R. Bommarco, G. Carré et al., "Measuring bee diversity in different European habitats and biogeographical regions," Ecological Monographs, vol. 78, no. 4, pp. 653-671, 2008.

[19] B. M. H. Larson, P. G. Kevan, and D. W. Inouye, "Flies and flowers: taxonomic diversity of anthophiles and pollinators," Canadian Entomologist, vol. 133, no. 4, pp. 439-465, 2001.

[20] S. Vrdoljak and M. Samways, "Optimising coloured pan traps to survey flower visiting insects," Journal of Insect Conservation, vol. 16, pp. 345-354, 2012.

[21] O. E. Prys-Jones and S. A. Corbet, Bumblebees, Cambridge University Press, Cambridge, UK, 1991.

[22] E. Pollard and T. J. Yates, Monitoring Butterflies for Ecology and Conservation: The British Butterfly Monitoring Scheme, Chapman \& Hall, London, UK, 1993.
[23] R. C. Team, "R: a language and environment for statistical computing," in Computing RFfS, Vienna, Austria, 2012.

[24] S. Dray and A. B. Dufour, "The ade4 package: implementing the duality diagram for ecologists," Journal of Statistical Software, vol. 22, no. 4, pp. 1-20, 2007.

[25] K. R. Clarke, "Non-parametric multivariate analyses of changes in community structure," Australian Journal of Ecology, vol. 18, no. 1, pp. 117-143, 1993.

[26] K. Clarke and R. Warwick, Change in Marine Communities: An Approach to Statistical Analysis and Interpretation, PRIMER-E, Plymouth, UK, 2001.

[27] M. A. Molina-Montenegro, E. I. Badano, and L. A. Cavieres, "Positive interactions among plant species for pollinator service: assessing the "magnet species" concept with invasive species," Oikos, vol. 117, no. 12, pp. 1833-1839, 2008.

[28] J. Fründ, K. E. Linsenmair, and N. Blüthgen, "Pollinator diversity and specialization in relation to flower diversity," Oikos, vol. 119, no. 10, pp. 1581-1590, 2010.

[29] M. Stang, P. G. L. Klinkhamer, and E. Van Der Meijden, "Size constraints and flower abundance determine the number of interactions in a plant-flower visitor web," Oikos, vol. 112, no. 1, pp. 111-121, 2006.

[30] L. Comba, S. A. Corbet, L. Hunt, and B. Warren, "Flowers, nectar and insect visits: evaluating British plant species for pollinator-friendly gardens," Annals of Botany, vol. 83, no. 4, pp. 369-383, 1999.

[31] T. Jermy, F. E. Hanson, and V. G. Dethier, "Induction of specific food preference in lepidopterous larvae," Entomologia Experimentalis et Applicata, vol. 11, no. 2, pp. 211-230, 1968.

[32] J. H. Lawton, "Plant architecture and the diversity of phytophagous insects," Annual Review of Entomology, vol. 28, pp. 23-39, 1983.

[33] N. M. Haddad, D. Tilman, J. Haarstad, M. Ritchie, and J. M. H. Knops, "Contrasting effects of plant richness and composition on insect communities: a field experiment," American Naturalist, vol. 158, no. 1, pp. 17-35, 2001.

[34] S. G. Potts, B. A. Woodcock, S. P. M. Roberts et al., "Enhancing pollinator biodiversity in intensive grasslands," Journal of Applied Ecology, vol. 46, no. 2, pp. 369-379, 2009.

[35] M. Albrecht, B. Schmid, Y. Hautier, and C. B. Muller, "Diverse pollinator communities enhance plant reproductive success," Proceedings of the Royal Society B, vol. 279, pp. 4845-4852, 2012.

[36] C. McCall and R. B. Primack, "Influence of flower characteristics, weather, time of day, and season on insect visitation rates in three plant communities," American Journal of Botany, vol. 79, no. 4, pp. 434-442, 1992.

[37] M. W. Brown and J. J. Schmitt, "Seasonal and diurnal dynamics of beneficial insect populations in apple orchards under different management intensity," Environmental Entomology, vol. 30, no. 2, pp. 415-424, 2001.

[38] J. H. Cane, R. L. Minckley, and L. J. Kervin, "Sampling bees (Hymenoptera: Apiformes) for pollinator community studies: pitfalls of pan-trapping," Journal of the Kansas Entomological Society, vol. 73, no. 4, pp. 225-231, 2000.

[39] F. S. Gilbert, "Foraging ecology of hoverflies: morphology of the mouthparts in relation to feeding on nectar and pollen in some common urban species," Ecological Entomology, vol. 6, pp. 245$262,1981$.

[40] A. Stubbs and S. Faulks, British Hoverflies: An Illustrated Identification Guide: British Entomological and Natural History Society, 2002. 
[41] E. Gaujour, B. Amiaud, C. Mignolet, and S. Plantureux, "Factors and processes affecting plant biodiversity in permanent grasslands. A review," Agronomy for Sustainable Development, vol. 32, pp. 133-160, 2011.

[42] A. López-Mariño, E. Luis-Calabuig, F. Fillat, and F. F. Bermúdez, "Floristic composition of established vegetation and the soil seed bank in pasture communities under different traditional management regimes," Agriculture, Ecosystems and Environment, vol. 78, no. 3, pp. 273-282, 2000.

[43] A. R. Kells and D. Goulson, "Preferred nesting sites of bumblebee queens (Hymenoptera: Apidae) in agroecosystems in the UK," Biological Conservation, vol. 109, no. 2, pp. 165-174, 2003.

[44] P. Westrich, "Habitat requirements of central European bees and the problems of partial habitats," in The Conservation of Bees, A. Matheson, S. L. Buchmann, C. O'Toole, P. Westrich, and I. H. Williams, Eds., pp. 1-16, Academic Press for the Linnean Society of London and IBRA, London, UK, 1996.

[45] R. Winfree, "The conservation and restoration of wild bees," $A n$ nals of the New York Academy of Sciences, vol. 1195, pp. 169-197, 2010.

[46] R. F. Pywell, W. R. Meek, L. Hulmes et al., "Management to enhance pollen and nectar resources for bumblebees and butterflies within intensively farmed landscapes," Journal of Insect Conservation, vol. 15, no. 6, pp. 853-864, 2011. 

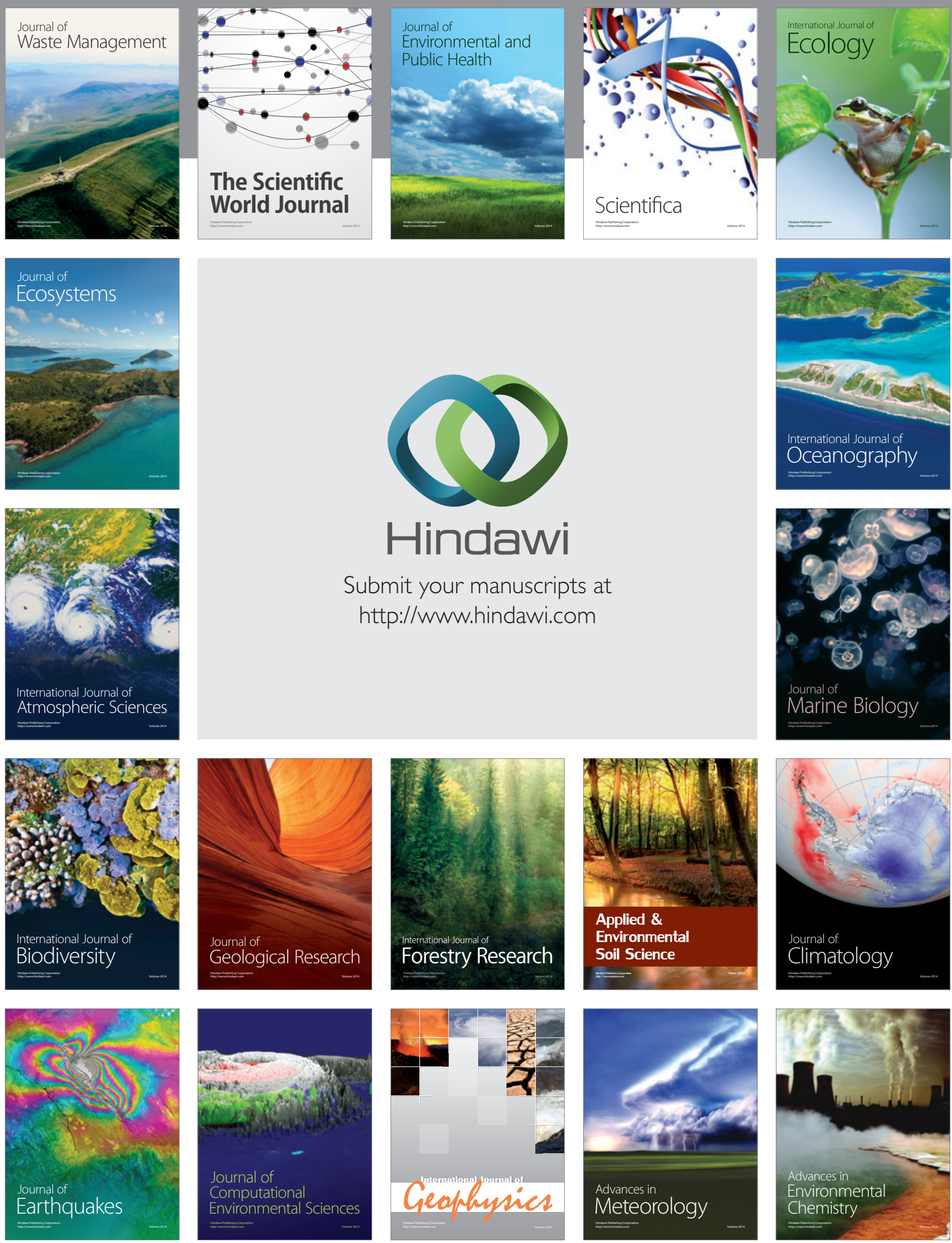